\title{
Actualización de Recomendaciones Clínicas
}

\author{
WALDO MERINO ${ }^{1}$
}

L as Recomendaciones Clínicas (RCs) resumen y evalúan la evidencia disponible sobre un tema en - particular, con el objetivo de ayudar a los profesionales de la salud en la selección de las mejores estrategias para enfrentar una situación clínica específica, en un paciente individual, considerando los potenciales riesgos y beneficios de sus decisiones.

Han influido progresivamente en la práctica clínica por su rigurosidad científica, su lenguaje simple y directo, de fácil acceso. Por su impacto clínico y económico son una herramienta que ha demostrado su utilidad en la ejecución de políticas públicas de salud. Han sido fuente pericial en casos llevados a tribunales y son reconocidas por los pacientes como fuente de información a propósito de procedimientos y atenciones en salud. Estos aspectos nos señalan el alcance e importancia que tienen las RCs. Por ello, la Sociedad de Anestesiología de Chile (SACH) se ha planteado como una política de la institución la elaboración y actualización permanente de RCs para "respaldar el trabajo profesional de nuestros asociados a lo largo del país, con estándares de calidad adecuados a los tiempos, señalando la mejor evidencia disponible, para un mejor desempeño clínico y profesional, pensando en el beneficio de nuestros pacientes y de la salud pública de nuestro país".

Así, en este número de nuestra revista publicamos las "Orientaciones para la Elaboración y Actualización de Recomendaciones Clínicas de la Sociedad de Anestesiología de Chile", documento formulado por el comité de Recomendaciones Clínicas. Es una guía actualizada que pretende entregar herramientas para la elaboración de este tipo de documentos de manera de establecer, con rigurosidad metodológica, las condiciones necesarias para un buen desempeño profesional y orientaciones con respecto a las mejores estrategias que deberían ayudar a tomar decisiones en el ejercicio clínico de los anestesiólogos del país, como también ofrecer información relevante para autoridades sanitarias, administradores, pacientes y familiares.

Para guiar a los grupos técnicos en el proceso de formulación de las recomendaciones y sus actualizaciones el documento señala sugerencias para ejecutar la búsqueda bibliográfica, selección de la evidencia y la redacción de los contenidos, en sintonía con el "Manual Metodológico: Desarrollo de Guías de Práctica Clínica"[1] del Ministerio de Salud y para evaluar la calidad de la evidencia y la fuerza de las recomendaciones hemos incorporando el sistema GRADE[2]. Las tres actualizaciones de RCs que se publicarán en los primeros tres números de nuestra revista durante el 2018 darán cuenta de este avance metodológico. Son las primeras actualizaciones que se realizan de cualquiera de las Recomendaciones Clínicas publicadas por la SACH a la fecha. De esta manera, en este número presentamos "Disponibilidad y Uso de Monitorización Perioperatoria" (agosto de 2007), formulada de acuerdo con los nuevos lineamientos, ya presentamos en el número anterior la actualización "Manejo del Dolor Agudo Perioperatorio en Niños" (octubre de 2007)[3] y en el próximo número se publicará la actualización de la RC "Evaluación Preoperatoria" (marzo de 2007).

La RC "Disponibilidad y Uso de Monitorización Perioperatoria" señala las condiciones de infraestructura y equipamiento necesarias para entregar garantías que permitan un buen desempeño profesional. Es importante señalar que estas condiciones de infraestructura e insumos, en general, no son dependientes del ejercicio o desempeño clínico y profesional del

Anestesiólogo, profesor Asistente, Departamento de Cirugía, Traumatología y Anestesia Universidad de La Frontera.

Fecha de recepción: 2 de mayo de 2018

Fecha de aceptación: 2 de mayo de 2018

ORCID

https://orcid.org/0000-0002-4956-8444

Correspondencia:

Email:wamerino@gmail.com 
anestesiólogo, sino más bien del administrador quién es gestor de los recursos en el sector público y privado. Así, el texto establece claramente "... que las $R C S$ son una exhaustiva revisión de expertos, donde se puede reconocer algunas condiciones de equipamiento e infraestructura que son necesarias para cumplir un desempeño profesional acorde a la "lex artis". Estas condiciones, en general, son una responsabilidad exclusiva y excluyente del administrador o gestor de los recursos en el sector público y privado. Por esta razón la SACH recomienda a sus asociados hacer presentaciones escritas para que los administradores y gestores se mantengan razonablemente informados en estas materias. Las comunicaciones respectivas se pueden canalizar a través de la SACH, ello permite conducir y facilitar los procesos en las instituciones sanitarias que sostengan condiciones de trabajo y clinicas deficitarias".

Con estos documentos, la SACH nuevamente da cumplimiento "a su propósito, a su responsabilidad ética y a su compromiso con el país, desarrollando, y participando en actividades que aporten al mejoramiento de la comunidad y la salud pública, difundiendo y promoviendo el conocimiento científico, poniendo a disposición de los usuarios, autoridades sanitarias y anestesiólogos, información pertinente para apoyar la práctica de los colegas, en beneficio de todos, especialmente de nuestros pacientes"[4].

\section{Referencias}

1. Ministerio de Salud. Subsecertaria de Salud. División de control y prevención de enfermedades. Deparatamento Secretaria AUGE y de coordinación evidencial y metodológica. Manual Metodológico. Desarrollo de Guías de
Práctica Clínica. Santiago, Chile; 2014.

2. Neumann I, Pantoja T, Peñaloza B, Cifuentes L, Rada G. El sistema GRADE: un cambio en la forma de evaluar la calidad de la evidencia y la fuerza de recomendaciones. Rev Med Chile 2014; 142: 630-635.
3. Campos T, Eulufi S, Fajardo MA, Guerra K, Pérez IM, Merino W, Ramos LE, Ribal MA. Recomendación Clínica "Manejo del Dolor Agudo Perioperatorio en Niños". Rev Chil Anest 2018; 47: 46.

4. Bustamante R. Editorial: Recomendaciones Clínicas. Rev Chil Anest. 2012;41:3. 